\title{
Population viability analysis of Critically Endangered white-rumped vultures Gyps bengalensis
}

\author{
Nabin Baral ${ }^{1, *}$, Christopher Nagy ${ }^{2}$, Benjamin J. Crain ${ }^{3}$, Ramji Gautam $^{4}$ \\ ${ }^{1}$ Department of Forest Resources and Environmental Conservation, Virginia Tech, Blacksburg, Virginia 24061, USA \\ ${ }^{2}$ Division of Vertebrate Zoology, American Museum of Natural History, Central Park West, New York, New York 10024, USA \\ ${ }^{3}$ Department of Biology, University of Puerto Rico-Rio Piedras, San Juan, Puerto Rico 00936 \\ ${ }^{4}$ Department of Zoology, Prithvi Narayan Multiple Campus, Tribhuvan University, Pokhara, Nepal
}

\begin{abstract}
More than a decade has passed since the catastrophic population decline in Gyps species was reported from South Asia, but much uncertainty remains about quantifying their short-term extinction risk. To estimate the future extinction risk of the white-rumped vulture Gyps bengalensis in Nepal, we conducted counts at 7 nesting colonies between 2002 and 2012. We compared 3 methods of estimating abundance based on count data and calculated mean population growth rates and cumulative probabilities of extinction given the abundance estimates from each method. The first 2 methods of abundance estimation were traditional indices: mean and maximum values of all counts. The third method was a mixture modeling approach that corrected raw counts by a detection parameter. The results of the traditional indices were characterized by high uncertainty levels as reflected in the wide confidence intervals, which limited their capacity to make predictions about the fate of the populations with any confidence. The mixture modeling method provided more reliable results; there was a $51 \%$ probability of populations facing quasiextinction (i.e. $\leq 20$ vultures) in $13 \mathrm{yr}$ and a $99 \%$ probability of quasi-extinction in $18 \mathrm{yr}$. Because the mixture modeling method provided more precise predictions while requiring minimal additional effort, population biologists using count data are encouraged to employ such model-based estimators. The white-rumped vulture populations in Rampur are in danger of disappearing within 2 decades, so conservation efforts should be expedited to prevent the loss of this species.
\end{abstract}

KEY WORDS: Asian vulture crisis $\cdot$ Extinction probability $\cdot$ Nepal $\cdot$ Population ecology $\cdot$ Rampur Valley $\cdot$ Vulture conservation

\section{INTRODUCTION}

The worst vulture declines in recent history have occurred in southern Asia, where $95 \%$ of wild populations of 3 Gyps species were extirpated before the dawn of the new millennium (Prakash 1999, Pain et al. 2003, 2008, Cuthbert et al. 2011). White-rumped vultures Gyps bengalensis were classified as 'Critically Endangered', the category for species facing an extremely high risk of extinction in the wild, in the
IUCN's Red Data Book following the Asian vulture crisis (BirdLife International 2001). Until 1985, whiterumped vultures were described as possibly the most abundant large bird of prey in the world (Houston 1985), with an estimated global population of several million birds. After precipitous declines throughout the Indian subcontinent, the estimated global population of white-rumped vultures falls within the band of 3500 to 15000 birds (BirdLife International 2012). The population decline has slowed due to the con- 
certed efforts of stakeholders involved in vulture conservation, but there has been no strong evidence of increasing or even stable vulture populations on the Indian subcontinent (Pain et al. 2008, Cuthbert et al. 2011, Prakash et al. 2012).

A large number of factors have contributed to the decline in vulture populations in southern Asia. Renal failure and visceral gout resulting from the consumption of livestock carcasses contaminated with the veterinary drug diclofenac are believed to be the main factors contributing to the large-scale and rapid decline of Gyps vultures (Oaks et al. 2004, Green et al. 2006). Simulations have shown that just 1 in 760 livestock carcasses needs to contain diclofenac residues to cause the observed increase in mortality rate and subsequent population declines in wild vulture populations (Green et al. 2004). In addition to diclofenac, other veterinary drugs such as ketoprofen and aceclofenac are known or suspected to be toxic to vultures (Naidoo et al. 2010, Sharma 2012) and may play a role in their population declines. Although diclofenac poisoning took a heavy toll on wild populations in a short period of time, white-rumped vultures display several other characteristics (for example, a small clutch size, slow breeding, and delayed maturity) that can reduce the ability of a population to rebound even after negative influences have been removed (e.g. Meretsky et al. 2000, Antor et al. 2007). Likewise, other factors such as habitat destruction, food scarcity, and human persecution have also contributed to the slow decline in populations over the long run (BirdLife International 2001, Ogada et al. 2012). Consequently, the future of Gyps species appears to be bleak.

The unprecedented population decline of Gyps vultures raises several questions: What is the chance of recovery of white-rumped vultures? How long do we have before they become extinct under current conditions? What management interventions would improve their population viability? Is captive breeding and re-introduction to natural habitat patches a feasible strategy for conserving white-rumped vultures? Answers to these questions are critical for their survival, and population viability analysis (PVA) can supply answers to questions like these.

PVA has emerged as an alternative to the 'magic number' of 50 individuals suggested as the minimum number to prevent extinction (Gilpin 1996). In contrast to the minimum viable population rule, a PVA is a stochastic quantitative process to evaluate the extinction probability of a particular population over time. PVA can serve 3 useful functions, partic- ularly in the conservation and management of rare and endangered species. First, a PVA can determine the urgency of recovery efforts based on the estimate of extinction probability within a specified length of time (Dennis et al. 1991, Morris \& Doak 2002). Second, a PVA can assess recovery success by synthesizing monitoring data (Morris \& Doak 2002). Third, a PVA can identify key demographic processes or life cycle components suitable for management interventions (e.g. Crouse et al. 1987, Tremblay 1997, Beissinger \& Westphal 1998). Because of its useful functions, there have been numerous case studies using PVA to address various aspects of rare and endangered species management, including estimating extinction probability (Dennis et al. 1991, Morris \& Doak 2002, Masatomi et al. 2007), testing the efficacy of recovery and reintroduction (Dennis et al. 1991, Kohlmann et al. 2005, Zeoli et al. 2008, Schaub et al. 2009), assessing habitat requirements (Perkins et al. 2008, Coates \& Duncan 2009), and analyzing the costeffectiveness of conservation programs (Marshall et al. 2000, Bode \& Brennan 2011).

Estimating abundance is a critical first step in PVA. Two widely used methods for estimating the abundance of white-rumped vultures in southern Asia are counts of active nests and road transect surveys (Gilbert et al. 2002, Prakash et al. 2003, 2012, Chaudhary et al. 2012). By counting the number of active nests, the first approach underestimates abundance because it ignores the subadults and juveniles present in a population. There are several major issues with road transect surveys for white rumped vultures. First, data collected along roads are not representative of the population because nonrandom selection of survey locations (most often the case in road transects) increases bias (Anderson 2001, Thompson 2002). Second, a large number of detections is required to estimate a detectability function. This may not be feasible because of low population densities after the species declined by $>95 \%$ (Johnson 2008). Third, a transect survey is not useful when the area of interest is small or when the animals are spatially clumped, which is the case with whiterumped vultures that nest in relatively small, scattered colonies.

Consequently, when vultures are counted multiple times over time and space in the breeding colonies, the simplest indices of abundance are the mean and maximum values of all counts at each colony. These index values are simple to calculate but invoke strong assumptions and at best are indices of relative abundance (Thompson \& Harwood 1990, Link \& 
Sauer 1997, 1998, Severson \& Plumb 1998). A major criticism of these index values is that they do not take into account detection probability, which makes it difficult to make strong inductive inferences about population growth or decline (Anderson 2001, Thompson 2002).

It is becoming increasingly apparent that biologists need to account for imperfect detection in their estimates of species presence and abundance (Royle 2004, MacKenzie et al. 2006, Kéry \& Schmidt 2008). Even the maximum of a series of counts may be smaller than the actual abundance if animals are missed (Thompson \& Harwood 1990). Indeed, if one assumes a stable abundance at a site within seasons, any deviation in counts at that site indicates imperfect detection on the part of the observer and/or varying availability of the animal to be detected even if it is present. While biologists have been aware of these issues for many years, recent techniques have been developed that can explicitly account for and model detection and availability rates (see MacKenzie et al. 2006 for an in-depth discussion of similar issues regarding presence/absence methods). Count data are particularly important in avian ecology, and specific techniques have been developed to handle such data (Royle 2004, Royle et al. 2004, Nichols et al. 2009). Royle (2004) developed an N-mixture modeling approach that estimates detection rate and population change from count data taken from multiple visits to multiple sites. Dail \& Madsen (2011) expanded this technique to allow for multiple seasons (i.e. primary periods) where abundance could vary between seasons. Taking into account imperfect detection is critical for a reliable estimate of abundance for PVA.

When it comes to conservation of critically endangered white-rumped vultures, developing robust and efficient PVA models will be useful for management as these models provide critical information on the probability of extinction in practical terms. McCarthy et al. (2003) concluded that at least $10 \mathrm{yr}$ of data are needed to obtain a PVA with good predictive power. In this study, we conducted a count-based PVA based on $10 \mathrm{yr}$ of count data from white-rumped vulture nesting colonies to quantify extinction risk for this species in one of the 'Important Bird Areas' of Nepal, the Rampur Valley.

The primary goal of this study was to obtain an estimate of the likely time to extinction of the Rampur Valley's white-rumped vultures. We were also interested in comparing and examining the differences of predictions using 3 methods of abundance estimation from counts. These methods included the 2 tradi- tional indices - the mean and maximum values of all counts - and a more recent modeling approach to estimate and incorporate detection probability into abundance estimates (Royle 2004, Dail \& Madsen 2011). To this end, we calculated abundances and growth rates from our count data and determined the probability of quasi-extinction using count-based PVA methods (Dennis et al. 1991, Morris \& Doak 2002). To our knowledge, this is the first attempt at using a long-term data set to quantify extinction risk through empirical modeling for white-rumped vultures. As such, the findings should provide several pieces of critical information on the population dynamics of white-rumped vultures.

\section{MATERIALS AND METHODS}

\section{Study site}

The Rampur Valley $\left(27^{\circ} 51^{\prime} 80^{\prime \prime} \mathrm{N}, 8^{\circ} 54^{\prime} 24^{\prime \prime} \mathrm{E}\right)$ lies in the Palpa District in the south-west part of Nepal (Fig. 1). The valley has the highest breeding density of white-rumped vultures Gyps bengalensis (Baral et al. 2005), and thus it has been included in BirdLife International's list of 'Important Bird Areas' of Nepal (Baral \& Inskipp 2005). Rampur has a subtropical climate, with an average $( \pm \mathrm{SD})$ yearly rainfall of $1773 \pm 405 \mathrm{~mm}$, an average minimum yearly temperature of $16.5 \pm 0.9^{\circ} \mathrm{C}$, and an average maximum yearly temperature of $29.0 \pm 0.8^{\circ} \mathrm{C}$ for the decade 2001 to 2010. The dominant vegetation comprises hill sal Shorea robusta, kapok Bombax ceiba, khair Acacia catechu, karma Adina cordifolia, bel Aegle marmelos, and mango Mangifera indica. Other resident vultures found in the valley are the 'Critically Endangered' slender-billed vulture Gyps tenuirostris, the 'Critically Endangered' red-headed vulture Sarcogyps calvus, and the 'Endangered' Egyptian vulture Neophron percnopterus. Thus, the Rampur Valley provides critical habitat to a number of important species in addition to the white-rumped vulture, making it a priority area for conservation efforts.

We found 7 breeding colonies of white-rumped vultures in Rampur Valley: Islampur, Sadawarta, Jyagdi, Shera, Khairini, Shekham, and Keladi (Fig. 1). Except for Keladi, which was discovered in 2006, we have been monitoring each of the colonies since 2002. After 2003, the Islampur colony was deserted because local residents felled the nesting and roosting trees. Among the breeding colonies, Khairini held the highest number of vul- 


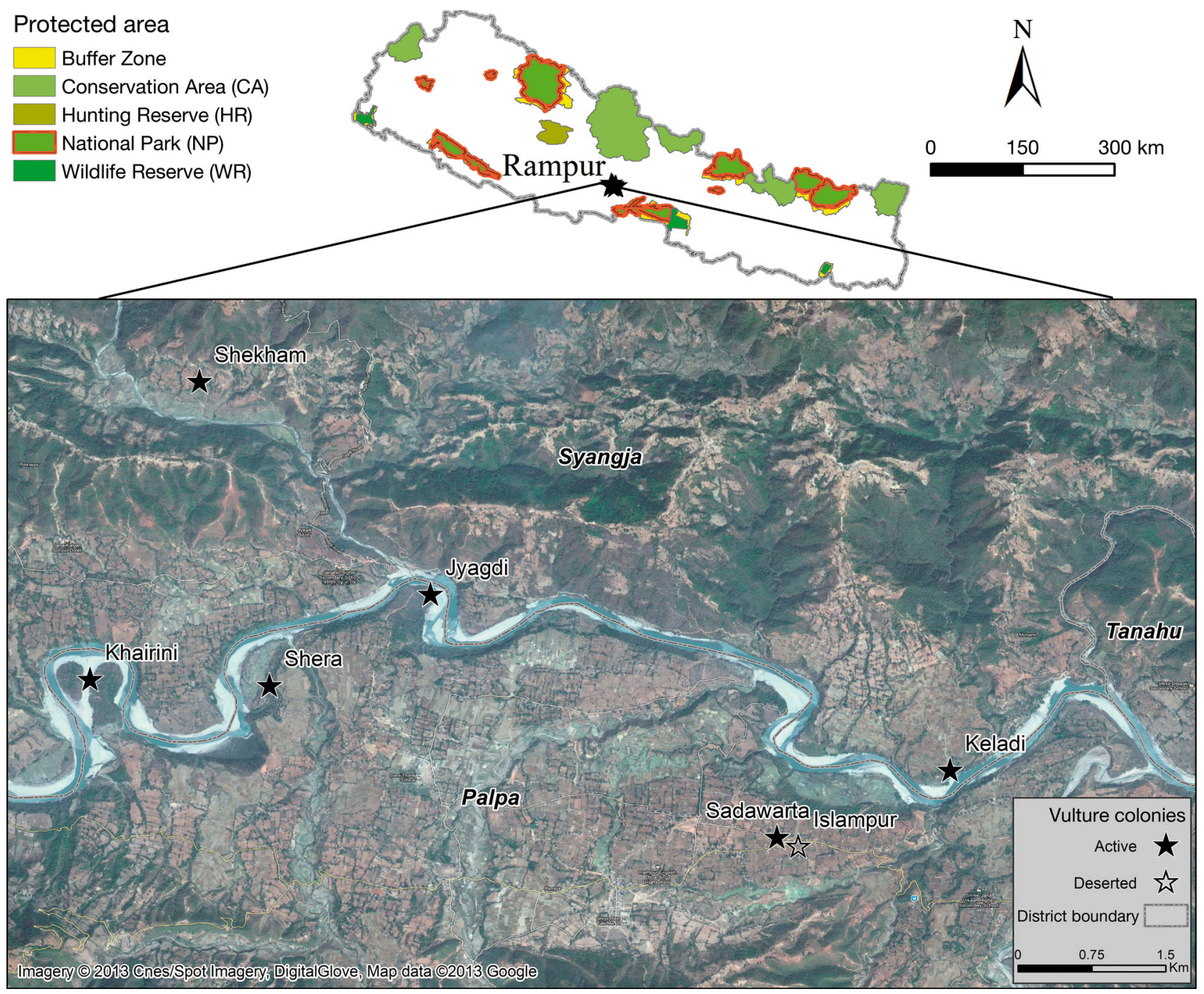

Fig. 1. Network of Nepalese protected areas, Rampur, and vulture colonies. The active colonies are indicated by filled stars, and a deserted colony by an open star

tures throughout the study period. The average distance between colonies was $4.1 \pm 2.1 \mathrm{~km}$ (minimum $=0.2 \mathrm{~km}$ between Islampur and Sadwarta, maximum $=7.1 \mathrm{~km}$ between Islampur and Shekham). Without marking or tagging vultures, it is almost impossible to determine the movement of individual vultures between the colonies. The movement of 5 satellite-tagged adult male whiterumped vultures ranged between 25 and $316 \mathrm{~km}$ from their breeding or roosting sites in Pakistan in 2003/2004 (Gilbert et al. 2007). This evidence suggests that vultures have the ability to move among the colonies within Rampur or from other colonies within the country. But, the degree of connectivity among separate populations and movements of white-rumped vultures is still poorly known.

\section{Field methods}

In the past $10 \mathrm{yr}$, we spent a total of $225 \mathrm{~d}$ (at least $5 \mathrm{~h} \mathrm{~d}^{-1}$ ) in the field to count vultures at 7 nesting colonies (1 was deserted in the second year, however, and therefore no data from this site were collected in subsequent years). On a yearly basis, average $( \pm \mathrm{SD})$ research effort was $22.5 \pm 5.7 \mathrm{~d}$. Most often, fieldwork commenced in September and continued until May to coincide with the vultures' breeding season. The breeding season commences with the congregation of vultures and pair forming (or occupying a territory), which makes it easier to observe and count them. At least 5 and at most 8 repeated counts were made in each year, resulting in an average of $6.4 \pm$ 0.8 counts $\mathrm{yr}^{-1}$. 
Reliable counts of a population can be made at nests and roosts of raptor colonies, with increasing precision in counts by standardizing the survey procedure in terms of season, time of the day, and observer experience (Glinski \& Ohmart 1983). Accordingly, each year we attempted to count at the same regular intervals and in the same months to control for potential variability. Additionally, all colonies were visited on the same days. We monitored all the roosting and nesting sites early in the morning (06:30 to 09:30 h) and late in the evening (17:30 to $19: 30 \mathrm{~h}$ ) and recorded all the vultures seen on nests and perched on roosts. In each survey, the count represented the sum of adults, subadults, and juveniles. Counting roosting as well as nesting vultures took into account non-breeders in addition to breeding individuals. Because a single observer spearheaded all population counts, the variability among observers was controlled by design.

\section{Estimating abundance}

True abundance is often unknown in wildlife studies (e.g. Thompson \& Harwood 1990), so it needs to be estimated from data, i.e. counts of vultures at breeding sites in this case. For the purpose of our regional PVA, we summed site-specific abundances (i.e. abundances at each nesting colony) to get a total abundance estimate for the Rampur Valley. We did not model colonies separately because vultures are seemingly able to move between colonies given the information that is available on vulture movements (Gilbert et al. 2007) and because of the relatively small distances between our colonies (0.2 to $7.1 \mathrm{~km})$.

Because we conducted population counts at least 5 times in a year at multiple colonies, we had multiple counts at each site in each season and could thus estimate abundance in a number of ways. We used both the mean and maximum values of all counts as the first 2 estimators of annual breeding abundance. The mean value comprises all counts as comparable estimates of abundance, while the maximum value may represent a more realistic approximation of abundance (Severson \& Plumb 1998), since there were at least as many animals at the site as the maximum count. We used these indices to determine site-specific abundances and then summed respective abundances to get annual total abundance for the entire Rampur region.

To use Dail and Madsen's method (hereafter DM method; Dail \& Madsen 2011), we truncated our 5 to 8 counts $\mathrm{yr}^{-1}$ to include only October through Febru- ary counts. We therefore had 39 counts in total for $10 \mathrm{yr}$ ( 3 counts for $3 \mathrm{yr}, 4$ counts for $5 \mathrm{yr}$, and 5 counts for $2 \mathrm{yr}$ ). This period is the time of highest breeding density, and thus abundance is likely to be relatively stable during this stretch. Before October and after February, abundance could change substantially as vultures arrive and leave sporadically.

The DM method was implemented in the R package 'unmarked' using the 'pcountOpen' function (Fiske \& Chandler 2011) to estimate annual abundances at each site under a basic intercept-only model (setting abundance as a Poisson variable and detection as a binomial variable) with no site covariates. Site-specific abundance estimates based on this model were summed to obtain annual total abundances for the Rampur region. These 10 annual estimates were subsequently used to estimate population growth rates. We also estimated an overall detection rate via the DM method, i.e. how likely we were to count a vulture if it was at a particular site during a particular survey.

\section{Estimating the parameters $\mu$ and $\sigma^{2}$}

After obtaining annual abundances for the Rampur region, we estimated the log geometric mean population growth $(\mu)$ and the variance of the change in population sizes $\left(\sigma^{2}\right)$ using linear regression (Morris \& Doak 2002). Variance of log growth rate increases with increasing time between counts; thus, to ensure equal variances across time intervals, time intervals (i.e. $t_{i+1}$ $-t_{i}$ ) are typically transformed via $\left(t_{i+1}-t_{i}\right)^{1 / 2}$, and log growth rates are divided by $\left(t_{i+1}-t_{i}\right)^{1 / 2}$; this transformation standardizes the variance in log growth rate across differing time scales. Since our surveys were performed at equal (annual) intervals, this transformation kept all time intervals equal to 1 . The slope of the resulting regression line was the estimated $\mu$ for our data using that abundance method, and the residual mean square (i.e. error mean square) was the estimate of $\sigma^{2}$. In our case, taking the arithmetic mean of the intrinsic rate of increase ( $r$-values) and estimating the variance would give the same results. This was done 3 times, with each regression using the respective data from each abundance method (mean and maximum values of all counts and the DM method).

We also estimated confidence intervals for each parameter. Following Dennis et al. (1991) and Morris \& Doak (2002), a $95 \%$ confidence interval for $\mu$ was estimated by the formula:

$$
\mu \pm t_{\alpha, q-1} \times \mathrm{SE}(\mu)
$$


where $t_{\alpha, q-1}$ is the critical value of a 2 -tailed $t$ distribution with $\alpha=0.05$ and $q=9$, the number of seasonal transitions in our 10 annual surveys. Confidence limits for $\sigma^{2}$ were calculated using the chi-squared distribution with $q-1$ degrees of freedom

$$
(q-1) \sigma^{2} / \chi_{0.025, q-1,}^{2}(q-1) \sigma^{2} / \chi_{0.975, q-1}^{2}
$$

\section{Testing assumptions}

Count-based PVA requires 4 major assumptions: (1) the mean and variance of the population growth rate remain constant, (2) growth rates and environmental effects are uncorrelated from one year to the next, (3) there are no catastrophes or bonanzas, and (4) counts represent the population size, i.e. observation error is insignificant (Morris \& Doak 2002). We tested these assumptions before embarking upon population viability model simulation.

To test the first 2 assumptions, we explored density dependence, demographic stochasticity, and temporal environmental trends. First, we examined a plot of the $r$ versus annual abundances $\left(N_{t}\right)$ to see if growth rates changed with annual abundance (density dependence). No consensus exists regarding at what population size demographic stochasticity becomes a major threat: Shaffer (1981) s uggests 50 individuals, Goodman (1987) and Lande (1993) suggest 20 individuals, while MacArthur \& Wilson (1967) suggest 10 individuals to insulate a population from random fluctuations in births and deaths. We followed the methods for other PVAs of large bird species (e.g. Engen \& Sæther 2000, Morris \& Doak 2002) and set the quasi-extinction threshold at 20 birds in total for all 6 colonies together in Rampur to address the demographic stochasticity issue. Finally, we performed a 2tailed Durbin-Watson test to determine whether successive annual growth rates were autocorrelated and regressed $r$-value and its variance against time (yr) to look for temporal environmental trends (i.e. correlation among growth rates or their variances).

Over the $10 \mathrm{yr}$ of study there was no evidence of extremely low or high growth rates. Our research project started after the catastrophic event of mass mortality of Gyps vul- ture populations on the Indian subcontinent, and there were no outliers among the annual growth rate data. We could not rule out the possibility of bonanzas causing a larger number of changes in population sizes in the future; however, failure to account for bonanzas would only lead to over-estimation of the true extinction risk.

To make sure counts best represent the true population size, we also estimated abundances accounting for imperfect detection. Using the DM method, we explicitly estimated abundances from our counts based on repeated counts adjusted by a detection parameter (Royle 2004, Dail \& Madsen 2011). Both the mean-count and maximum-count indices of abundance may not represent true population size because some vultures might not be detected.

\section{Determining extinction probabilities}

The population sizes in the last survey year 2011/2012 (58, 87, and 138 individuals, for the mean and maximum values of all counts and for DM methods, respectively) served as a starting population size for projection (see Fig. 2 for the temporal trend of the abundance estimated by each of the methods).

After validating assumptions, we calculated the probability of extinction at time $t$ with the inverse Gaussian distribution, given $\mu$ and $\sigma^{2}$ (see Lande \& Orzack 1988, Morris \& Doak 2002). Cumulative probabilities (or cumulative distribution functions) can then be calculated by integrating these probabilities from $t=0$ to $t=t_{\max }$. We estimated the cumulative distribution functions (CDFs) of the time to extinction for

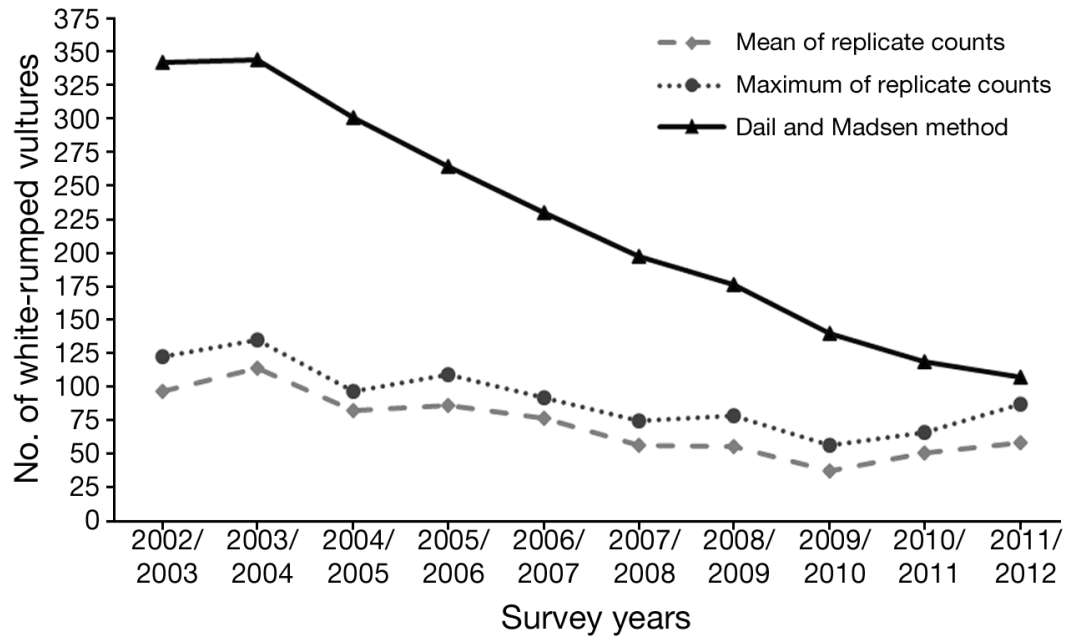

Fig. 2. Gyps bengalensis. Temporal trend in abundance of white-rumped vultures estimated by each of the 3 methods considered 
the Rampur populations based on the respective abundances, $\mu$ values, and $\sigma^{2}$ values given by each of the 3 methods for up to $50 \mathrm{yr}$ into the future. For estimating 95\% confidence bands, 10000 bootstrap resamples of $\mu$ and $\sigma^{2}$ and their respective standard errors were used. Distribution functions and their $95 \%$ confidence bands were calculated using MATLAB 7.1 (MathWorks 2005).

\section{RESULTS}

\section{Diagnostics of assumptions}

The assumptions of our count PVA appeared to be met. Regression results showed that there has been no substantial density dependence over the range of population sizes of Gyps bengalensis in the past $10 \mathrm{yr}$ because the mean value and variance of the population growth rates remained constant: the mean-count method $(\beta=-0.0038, t=-1.10, \mathrm{p}=0.309)$, the maximum-count method $(\beta=-0.0041, t=-1.45, \mathrm{p}=0.190)$, and the DM method $(\beta=-0.0002, t=-0.31, \mathrm{p}=$ 0.765).

Similarly, there were no temporal trends in population growth rate in any of the 3 scenarios: the meancount method $(\beta=0.0165, t=0.48, \mathrm{p}=0.643)$, the maximum-count method $(\beta=0.0249, t=0.86, \mathrm{p}=$ $0.420)$, and the DM method $(\beta=0.0008, t=0.05, \mathrm{p}=$ $0.960)$. There were no temporal trends in the variation of population growth rates either: the meancount method $(\beta=0.0064, t=0.96, \mathrm{p}=0.371)$, the maximum-count method $(\beta=0.0047, t=1.05, \mathrm{p}=$ $0.327)$, and the DM method $(\beta=0.0021, t=1.01, \mathrm{p}=$ $0.344)$.

The first-order autocorrelation coefficients of the population growth rates were not statistically significant in any of the 3 scenarios, although their signs were negative: the mean-count method (Pearson's $\mathrm{r}=$ -0.38 , $\mathrm{p}=0.349$ ), the maximum-count method (Pearson's $r=-0.38, p=0.356$ ), and the DM method (Pearson's $r=-0.21, p=0.617)$. These results suggested that there was no substantial autocorrelation in the growth rates. Results of the Durbin-Watson test showed a similar lack of autocorrelation because the value of the $d$ statistic was close to 2 (mean-count: $d=$ 2.30, $\mathrm{p}=0.624$; maximum-count: $d=2.30$, $\mathrm{p}=0.620$; and DM method: $d=1.40, \mathrm{p}=0.334$ ).

\section{Abundance estimation}

Method-specific abundances varied substantially (Table 1), with the mean-count method providing the lowest abundances (range: 37 to 114 vultures) and the DM method providing the largest (range: 107 to 344 vultures). The substantially higher abundances from the DM method were expected, since the counts were adjusted by detection rate (i.e. how likely is it that a vulture will be counted if it is present at the time of the survey); thus, an observer would tend to underestimate the true population size proportionally by approximately 1 - detection rate. The maximum-likelihood estimate of the detection rate was

Table 1. Gyps bengalensis. Abundance, the finite rate of population growth $(\lambda)$, the intrinsic growth rate $(r)$, and the estimation of parameters $\left(\mu\right.$ and $\sigma^{2}$ ) under the 3 different scenarios for assessing the extinction risk of white-rumped vultures in Rampur, Nepal, from 2002 to 2012. For method details see Royle (2004) and Dail \& Madsen (2011). $\mu$ : the arithmetic mean of population growth rate $(r) ; \sigma^{2}$ : the variance of $\mu_{i} N_{\mathrm{t}}$ and $N_{t+1}$ : difference in abundance $(N)$ between consecutive years $(t$ and $t+1)$; values in parentheses: $95 \%$ confidence intervals

\begin{tabular}{|c|c|c|c|c|c|c|c|c|c|}
\hline \multirow{2}{*}{$\begin{array}{l}\text { Survey } \\
\text { year }\end{array}$} & \multicolumn{3}{|c|}{ Mean of replicate counts } & \multicolumn{3}{|c|}{ Maximum of replicate counts } & \multicolumn{3}{|c|}{ Dail and Madsen's method } \\
\hline & Abundance & $\begin{array}{c}\lambda= \\
N_{t+1} / N_{t}\end{array}$ & $\begin{array}{c}r= \\
\log (\lambda)\end{array}$ & Abundance & $\begin{array}{c}\lambda= \\
N_{t+1} / N_{t}\end{array}$ & $\begin{array}{c}r= \\
\log (\lambda)\end{array}$ & Abundance & $\begin{array}{c}\lambda= \\
N_{t+1} / N_{t}\end{array}$ & $\begin{array}{c}r= \\
\log (\lambda)\end{array}$ \\
\hline $2002 / 2003$ & 97 & - & - & 123 & - & - & 342 & - & - \\
\hline $2003 / 2004$ & 114 & 1.1753 & 0.1615 & 135 & 1.0976 & 0.0931 & 344 & 1.0063 & 0.0063 \\
\hline $2004 / 2005$ & 82 & 0.7193 & -0.3295 & 97 & 0.7185 & -0.3306 & 301 & 0.8747 & -0.1339 \\
\hline 2005/2006 & 86 & 1.0488 & 0.0476 & 109 & 1.1237 & 0.1166 & 264 & 0.8751 & -0.1334 \\
\hline $2006 / 2007$ & 77 & 0.8953 & -0.1105 & 92 & 0.8440 & -0.1696 & 230 & 0.8714 & -0.1377 \\
\hline $2007 / 2008$ & 57 & 0.7403 & -0.3008 & 75 & 0.8152 & -0.2043 & 197 & 0.8567 & -0.1547 \\
\hline $2008 / 2009$ & 56 & 0.9825 & -0.0177 & 79 & 1.0533 & 0.0520 & 176 & 0.8951 & -0.1109 \\
\hline 2009/2010 & 37 & 0.6607 & -0.4144 & 57 & 0.7215 & -0.3264 & 140 & 0.7934 & -0.2314 \\
\hline 2010/2011 & 51 & 1.3784 & 0.3209 & 66 & 1.1579 & 0.1466 & 119 & 0.8507 & -0.1617 \\
\hline $2011 / 2012$ & 58 & 1.1373 & 0.1286 & 87 & 1.3182 & 0.2763 & 107 & 0.8962 & -0.1096 \\
\hline Mean $(\mu)$ & \multicolumn{3}{|c|}{$-0.0571(-0.2497$ to 0.1354$)$} & \multirow{2}{*}{\multicolumn{3}{|c|}{$\begin{array}{r}-0.0385(-0.2094 \text { to } 0.1325) \\
0.0495(0.0226 \text { to } 0.1816)\end{array}$}} & \multicolumn{3}{|c|}{$-0.1296(-0.1768$ to -0.0825$)$} \\
\hline Variance $\left(\sigma^{2}\right)$ & \multicolumn{3}{|c|}{$0.0627(0.0286$ to 0.2302$)$} & & & & \multicolumn{3}{|c|}{0.0039 (0.0018 to 0.0131$)$} \\
\hline
\end{tabular}


$0.35 \pm 0.02$ (mean and SE). Only the DM method showed a notable decline in population size over time (Fig. 2).

According to the results of the DM method, the Khairini site had the highest number of vultures (range: 83 to 127) throughout the study period (Fig. 3). All other sites had disproportionately lower numbers of vultures. At the Khairini site, the temporal trend in vulture populations resembled a shallow cubic curve: a slight increase at the beginning, a slight decrease in the middle and then a slight increase towards the end of the study period. But, at other sites, the numbers of vultures have shown sharp declines since 2008/2009.

\section{Population trend}

In all 3 scenarios, the mean values of the intrinsic rate of increase $(\mu)$ were negative, but the confidence intervals in the mean-count $(-0.2497$ to 0.1345$)$ and maximum-count $(-0.2094$ to 0.1325$)$ methods were wider (and also included zero) than in the DM method. In both the mean- and maximum-count estimates, the upper confidence intervals of $\mu$ were positive, and the confidence bands of the CDFs were exceedingly wide (Fig. 4). Although the estimates of $\mu$ were negative, suggesting that the population would decline in these 2 scenarios, there may be some periods of population increase because the variance of these estimates was relatively large. The DM method provided more precise estimates of $\mu$

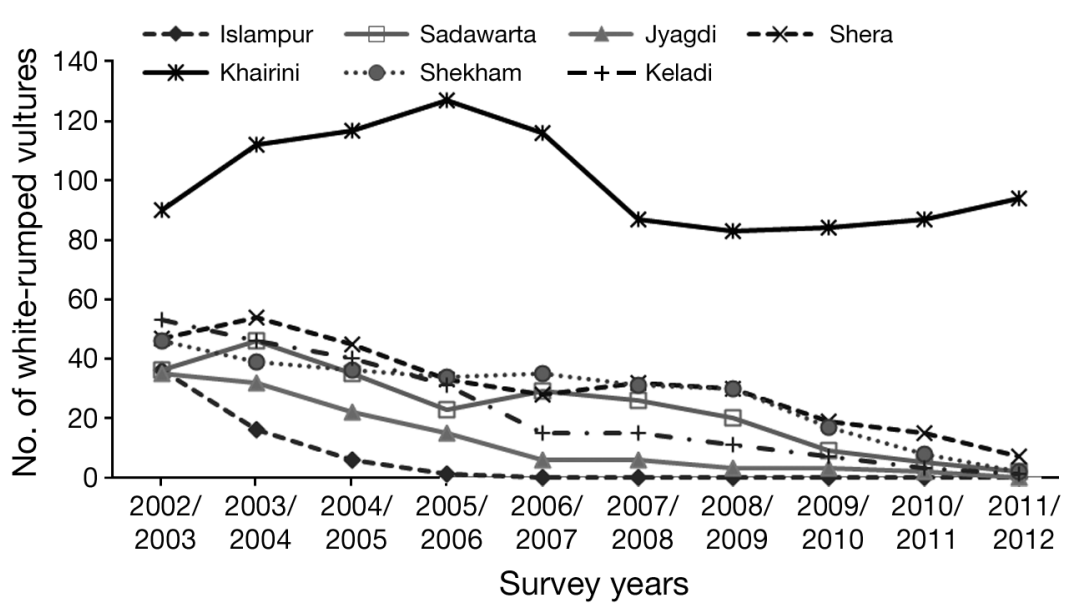

Fig. 3. Gyps bengalensis. Estimate of abundance by the Dail and Madsen method across 7 sites for the time period between 2002/2003 and 2011/2012. The mean and mode of the estimates were fairly close, so we chose the mode to represent abundance. The Islampur site was deserted during the second year, and the Keladi site was discovered in the fifth year. The first $4 \mathrm{yr}$ for the Keladi site were set to 0. (See Fig. 1 for site locations) and $\sigma^{2}$ because some of the variation in raw counts was accounted for in the estimate of the detection rate, thus yielding a less variable pattern in $\mu$ from year to year.

\section{Time to quasi-extinction}

The results of the mean- and maximum-count methods contained a great deal of uncertainty, as reflected by the wide confidence intervals, which limit their capacity to predict the fate of populations accurately. Using the DM method, predicted extinction times were much less varied, due to higher reliability of the abundance estimate; there was a $51 \%$ probability of populations facing quasi-extinction in $13 \mathrm{yr}$ and a $99 \%$ probability of quasi-extinction in 18 yr (Fig. 4). Although the quasi-extinction probability was higher for the mean- and maximum-count predictions within the next $10 \mathrm{yr}$, the extinction risk increased for the DM scenario after that time period. This switchover of extinction risk between the indexbased methods and the model-based methods was due to the higher predicted starting abundance in the DM method.

\section{Sensitivity analysis}

After examining the PVA results, we wanted to determine what goals management would have to achieve in terms of improving population growth to save the Rampur Valley population. We conducted a simple sensitivity analysis where annual $\lambda$ values from the DM estimates were increased by $5,10,15$, and $20 \%$ to represent hypothetical improvements in population growth as a result of successful conservation action. These enhanced $\lambda$ values were converted into $\mu$ values as before, and the extinction CDFs were re-calculated. It appears that an increase of 10 to $15 \%$ in annual population growth would dramatically improve the persistence probability of white-rumped vultures in the Rampur Valley for the next few decades (Fig. 5). An increase around $20 \%$ would likely ensure persistence for $50 \mathrm{yr}$, assuming other relevant factors remain similar. 


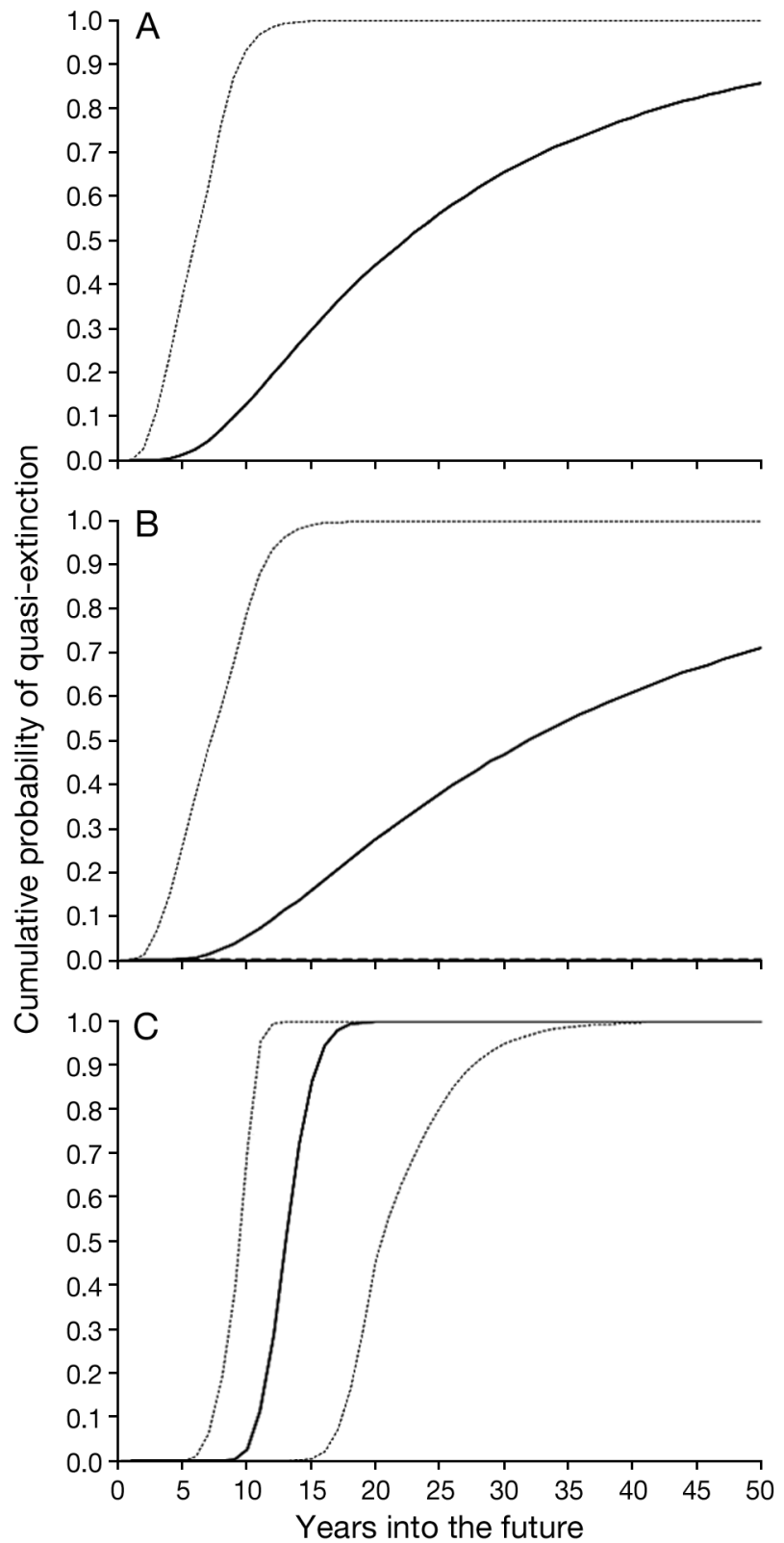

Fig. 4. Gyps bengalensis. Cumulative distribution function of quasi-extinction ( $<20$ vultures) probability for whiterumped vulture populations based on abundances estimated from the (A) mean-count and (B) maximum-count methods, and (C) from the Dail and Madsen method. Solid lines: mean estimates; dashed lines: bootstrapped $95 \%$ confidence intervals. The $x$-axis shows the time required for an initial population to cross the quasi-extinction threshold of 20 vultures

\section{DISCUSSION}

The comparative results suggest that the mixture modeling approach (the DM method) gives more reliable estimates of abundance and extinction probabil-

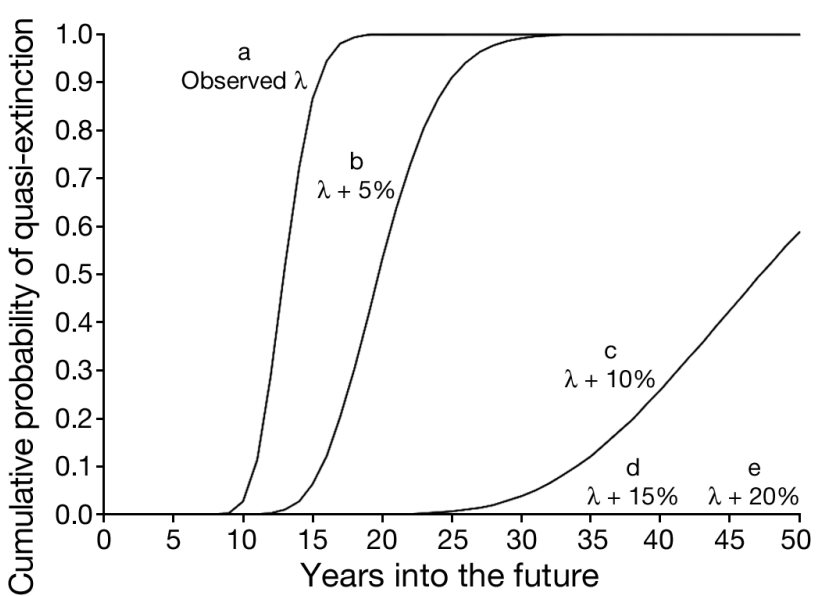

Fig. 5. Gyps bengalensis. Cumulative distribution function of quasi-extinction ( $<20$ vultures) probability for whiterumped vulture populations based on observed finite rate of growth $(\lambda)$ via the Dail and Madsen method (Line a), $\lambda+5 \%$ (Line b), $\lambda+10 \%$ (Line c), $\lambda+15 \%$ (Line d), and $\lambda+20 \%$ (Line e). Both Lines $d$ and e fall on the $x$-axis

ity than traditional indices (mean and maximum values of all counts), which yielded smaller annual abundances and much more variable growth rates. These results are in accordance with other studies that document the shortcomings of using mean- or maximumcount data (Thompson \& Harwood 1990, Anderson 2001, Thompson 2002). Continual monitoring of populations on a regular basis and adjusting management approaches in light of new information would be useful for devising appropriate conservation strategies. We expect that some modifications in monitoring protocols, for example, conducting more surveys between October and February, allocating more time for surveys in each colony, and deploying 2 observers to decrease observation fatigue, can increase detection probability in Rampur. Also, it is desirable to include environmental covariates in the estimation of detection probability. Count data obtained from point counts or transects are generally biased because of imperfect detection and, in some cases, because of the variable probability of an animal present being observed (i.e. counted). Methods, such as those described by Royle (2004) and Dail \& Madsen (2011), allow the estimation of such observer-based parameters and thus provide more accurate abundance estimates with minimal additional analysis. Most researchers acknowledge the need for multiple counts at their sites; thus, 'upgrading' to these new methods requires few adjustments and little additional field work. We encourage biologists that use count data to explore these concepts and adjust their study designs so they can make use of these more powerful techniques. 
Since our sensitivity analysis indicates that a 10 to $15 \%$ increase in population growth is necessary to maintain the vulture population, several management options should be considered. Keeping in mind the ongoing decline in white-rumped vultures, strategies aimed at increasing population growth rates by removing the toxic chemicals from the environment are obviously needed. The declaration of an area of $39122 \mathrm{~km}^{2}$ comprising 21 districts in Nepal (including Rampur) as Vulture Safe Zones i.e. diclofenac-free areas - could boost vulture population growth (see Bowden 2013). Removing the toxic chemicals would directly increase adult survival and lead to significant population increases because adult survival is the most elastic vital rate for populations of long-lived, iteroparous animals such as vultures (Lebreton \& Colbert 1991, Crooks et al. 1998, Gaillard et al. 1998, Sandvik et al. 2005). Stopping the use of diclofenac, ketoprofen, aceclofenac, and other harmful livestock medicines (Naidoo et al. 2010, Sharma 2012) would not only save adult vultures but also subadults and juveniles that are critical for population recruitment. Provision of wholesome food through the establishment of vulture feeding stations might prevent secondary poisoning, which is the main cause of the Gyps vultures' decline elsewhere (Muzinic 2007, Ogada \& Keesing 2010). These management interventions should create a favorable environment for the white-rumped vulture population to grow (Sibly \& Hone 2002).

A second strategy to stimulate population growth would be protecting nesting sites. Many nesting trees have been felled in the past to raise funds to run a school, compromising the vultures' breeding success (Gautam \& Baral 2009). Investigations on the potential use of artificial nesting sites should therefore be initiated. Thus, creating more suitable habitat, perhaps by creating artificial nesting sites, may prove to be an effective management strategy for white-rumped vultures.

Another management strategy that may prove successful is captive breeding. Despite their limitations (see Snyder et al. 1996), captive breeding programs have helped to prevent the extinction of a number of rare and endangered species. Captive breeding and release programs have proved to be effective for bird species such as griffon vultures Gyps fulvus, peregrine falcons Falco peregrinus, and Puerto Rican parrots Amazona vittata (Sarrazin et al. 1994, White et al. 2005). The Vulture Conservation and Breeding Center was established in 2008 in Nepal with the aim of holding up to 25 pairs of white-rumped vultures, and some promising results for long-term conservation of vultures have resulted. A major demerit of captive breeding is that the capture of wild vultures is required, which may decrease growth rates even further over a short-term period, which could be an overly large risk if this could lead to stochastic extinction. For example, when 17 chicks were captured from the wild for the breeding center, vultures deserted all the nesting trees from which chicks were collected (Gautam \& Baral 2013). As with most conservation strategies, however, each of these will require government, nongovernmental organizations, and local communities working together.

A major limitation of a count-based model is that it treats all individuals in the population as if they were identical, and we summed all potential breeders (juveniles, subadults, and adults) in our current study. Reducing the dynamics of reproduction and survival into a composite measure such as $\lambda$ and $r$ often obscures important age-specific details that can inform management (Allen et al. 1992), e.g. adult survival and reproduction versus juvenile survival and reproduction. An age-specific model based on data collected from marked vultures would provide more information about agespecific survival and reproductive rates, and direct strategies for conservation. Thus, future research should focus on banding a number of adult and juvenile vultures and then building an age-specific PVA model.

\section{CONCLUSIONS}

Once numbering in the millions, white-rumped vultures Gyps bengalensis are now estimated to have a global abundance of 15000 . If their precipitous decline is not halted or reversed, many large breeding populations will disappear, possibly leading to global species extinction in a few decades. By providing an estimate of the probability of quasi-extinction, the PVA presented here provides a realistic timeframe for conservation action and serves as a baseline for synthesizing monitoring data to assess the recovery of this species over time. Future research should focus on estimating age-specific survival and breeding rates in addition to overall abundance and growth rates of white-rumped vultures in the wild. Based on the present models, managers and stakeholders have approximately $15 \mathrm{yr}$ to reverse the decline. If immediate actions are taken, there is sufficient time to intervene and establish viable vulture populations in Rampur, Nepal. 
Acknowledgements. The Peregrine Fund (TPF), USA, The Royal Society for the Protection of Birds (RSPB), UK, and Bird Conservation Nepal (BCN) provided research grants to conduct the field work. The funding organizations, however, had no involvement in the study design, in the collection, analysis and interpretation of the data, in the writing of the report, or in the decision to submit the article for publication. We thank Prashant Bhattarai for his help in making Fig. 1 and Carlos Milan for his assistance with the computer programming. The constructive comments from 3 reviewers helped to improve the quality of the paper.

\section{LITERATURE CITED}

Allen EJ, Harris JM, Allen LJS (1992) Persistence-time models for use in viability analyses of vanishing species. J Theor Biol 155:33-53

Anderson DR (2001) The need to get the basics right in wildlife field studies. Wildl Soc Bull 29:1294-1297

Antor R, Margalida A, Frey H, Heredia R, Lorente L, Sesé J (2007) First breeding age in captive and wild bearded vultures Gypaetus barbatus. Acta Ornithologica 42: $114-118$

Baral HS, Inskipp C (2005) Important bird areas of Nepal. Bird Conservation Nepal, Kathmandu and BirdLife International, Cambridge

Baral N, Gautam R, Tamang B (2005) Population status and breeding ecology of white-rumped vulture Gyps bengalensis in Rampur Valley, Nepal. Forktail 21:87-91

Beissinger SR, Westphal MI (1998) On the use of demographic models of population viability in endangered species management. J Wildl Manag 62:821-841

BirdLife International (2001) Threatened birds of Asia: the BirdLife International Red Data Book. BirdLife International, Cambridge

BirdLife International (2012) Species factsheet: Gyps bengalensis. Available at: www.birdlife.org (accessed 13 September 2012)

> Bode M, Brennan KE (2011) Using population viability analysis to guide research and conservation actions for Australia's threatened malleefowl Leipoa ocellata. Oryx 45:513-521

Bowden C (ed) (2013) Report from the 2nd meeting of Saving Asia's Vultures from Extinction (SAVE). The Royal Society for the Protection of Birds (RSPB), Bedfordshire

- Chaudhary A, Subedi TR, Giri JB, Baral HS and others (2012) Population trends of Critically Endangered Gyps vultures in the lowlands of Nepal. Bird Conserv Int 22:270-278

> Coates F, Duncan M (2009) Demographic variation between populations of Caledenia orientalis - a fire-managed threatened orchid. Aust J Bot 57:326-339

> Crooks K, Sanjayan M, Doak D (1998) New insights on cheetah conservation through demographic modeling. Conserv Biol 12:889-895

> Crouse DT, Crowder LB, Caswell H (1987) A stage-based population model for loggerhead sea turtles and implications for conservation. Ecology 68:1412-1423

Cuthbert R, Taggart MA, Prakash V, Saini M and others (2011) Effectiveness of action in India to reduce exposure of Gyps vultures to the toxic veterinary drug diclofenac. PLoS ONE 6:e19069

Dail D, Madsen L (2011) Models for estimating abundance from repeated counts of an open metapopulation. Biometrics 67:577-587
Dennis B, Munholland PL, Scott JM (1991) Estimation of growth and extinction parameters for endangered species. Ecol Monogr 61:115-143

Engen S, Sæther B (2000) Predicting the time to quasiextinction for populations far below their carrying capacity. J Theor Biol 205:649-658

Fiske I, Chandler RB (2011) Unmarked: an R package for fitting hierarchical models of wildlife occurrence and abundance. J Stat Software 43:1-23. Available at: www. jstatsoft.org/v43/i10/

Gaillard JM, Festa-Bianchet M, Yoccoz N (1998) Population dynamics of large herbivores: variable recruitment with constant adult survival. Trends Ecol Evol 13:58-63

Gautam R, Baral N (2009) Research on and monitoring of white-rumped vultures (Gyps bengalensis) for seven years in Rampur, Nepal. Final report submitted to The Peregrine Fund, USA; The Royal Society for the Protection of Birds, UK; and Bird Conservation Nepal. The Peregrine Fund, Boise, ID

Gautam R, Baral N (2013) Population trends and breeding success of three endangered vulture species in Pokhara Valley, Kaski, Nepal. Ibisbill: J Himalayan Ornithol 2: $46-54$

Gilbert M, Virani MZ, Watson RT, Oaks JL and others (2002) Breeding and mortality of oriental white-backed vulture Gyps bengalensis in Punjab Province, Pakistan. Bird Conserv Int 12:311-326

Gilbert M, Watson RT, Ahmed S, Asim M, Johnson JA (2007) Vulture restaurants and their role in reducing diclofenac exposure in Asian vultures. Bird Conserv Int 17:63-77

Gilpin M (1996) Forty-eight parrots and the origins of population viability analysis. Conserv Biol 10:1491-1493

> Glinski RL, Ohmart RD (1983) Breeding ecology of the Mississippi kite in Arizona. Condor 85:200-207

Goodman D (1987) The demography of chance extinction. In: Soule ME (ed) Viable populations for conservation. Cambridge University Press, Cambridge, p 11-34

> Green RE, Newton I, Shultz S, Cunningham AA, Gilbert M, Pain DJ, Prakash V (2004) Diclofenac poisoning as a cause of vulture population declines across the Indian subcontinent. J Appl Ecol 41:793-800

- Green RE, Taggart MA, Das D, Pain DJ, Kumar S, Cunningham AA, Cuthbert R (2006) Collapse of Asian vulture populations: risk of mortality from residues of the veterinary drug diclofenac in carcasses of treated cattle. J Appl Ecol 43:949-956

Houston DC (1985) Indian white-backed vulture (G. bengalensis). In: Newton I, Chancellor RD (eds) Conservation studies on raptors. International Council for Bird Preservation Technical Publication No. 5, ICBP, Cambridge, p 465-466

Johnson DH (2008) In defense of indices: the case of bird surveys. J Wildl Manag 72:857-868

Kéry M, Schmidt BR (2008) Imperfect detection and its consequences for monitoring for conservation. Community Ecol 9:207-216

Kohlmann S, Schmidt G, Garcelon D (2005) A population viability analysis for the island fox on Santa Catalina Island, California. Ecol Model 183:77-94

> Lande R (1993) Risks of population extinction from demographic and environmental stochasticity and random catastrophes. Am Nat 142:911-927

Lande R, Orzack SH (1988) Extinction dynamics of agestructured populations in a fluctuating environment. Proc Natl Acad Sci USA 85:7418-7421 
Lebreton JD, Colbert J (1991) Bird population dynamics, management, and conservation: the role of mathematical modeling. In: Perrins CM, Lebreton JD, Hirons GJM (eds) Bird population studies: relevance to conservation and management. Oxford University Press, Oxford, p 105-125

Link W, Sauer J (1997) Estimation of population trajectories from count data. Biometrics 53:488-497

Link W, Sauer J (1998) Estimating population change from count data: application to the North American breeding bird survey. Ecol Appl 8:258-268

MacArthur RM, Wilson EO (1967) The theory of island biogeography. Princeton University Press, Princeton, NJ

MacKenzie DI, Nichols JD, Royle JA, Pollock KH, Bailey LL, Hines JE (2006) Occupancy estimation and modeling: inferring patterns and dynamics of species occurrence. Academic Press, Burlington, MA

> Marshall E, Homans F, Haight R (2000) Exploring strategies for improving cost effectiveness of endangered species management: the kirtland's warbler as a case study. Land Econ 76:462-473

> Masatomi Y, Higashi S, Masatomi H (2007) A simple population viability analysis of tancho (Grus japonesis) in southeastern Hokkaido, Japan. Popul Ecol 49:297-304

MathWorks (2005) MATLAB, Ver. 7.1. The MathWorks Inc., Natick, MA

McCarthy MA, Andelman SJ, Possingham HP (2003) Reliability of relative predictions in population viability analysis. Conserv Biol 17:982-989

Meretsky V, Snyder N, Beissinger S, Clendenen D, Wiley J (2000) Demography of the California condor: implications for re-establishment. Conserv Biol 14:957-967

Morris WF, Doak DF (2002) Quantitative conservation biology: theory and practice of population viability analysis. Sinauer Associate Publishers, Sunderland, MA

Muzinic J (2007) Poisoning of seventeen Eurasian griffons (Gyps fulvus) in Croatia. J Raptor Res 41:239-242

Naidoo V, Wolter K, Cromarty D, Diekmann M and others (2010) Toxicity of non-steroidal anti-inflammatory drugs to Gyps vultures: a new threat from ketoprofen. Biol Lett 6:339-341

Nichols JD, Thomas L, Conn PB (2009) Inferences about landbird abundance from count data: recent advances and future directions. Environ Ecol Stat 3:201-235

Oaks JL, Giltbert M, Virani MZ, Watson RT and others (2004) Diclofenac residues as the cause of population decline of vultures in Pakistan. Nature 427:630-633

$>$ Ogada DL, Keesing F (2010) Decline of raptors over a threeyear period in Laikipia, Central Kenya. J Raptor Res 44: 129-135

> Ogada DL, Keesing F, Virani MZ (2012) Dropping dead: causes and consequences of vulture population declines worldwide. Ann NY Acad Sci 1249:57-71

Pain DJ, Cunningham AA, Donald PF, Duckworth JW and others (2003) Causes and effects of temporospatial declines of Gyps vultures in Asia. Conserv Biol 17: 661-671

Pain DJ, Bowden CGR, Cunningham AA, Cuthbert R and others (2008) The race to prevent the extinction of South Asian vultures. Bird Conserv Int 18:S30-S48

> Perkins DW, Vickery PD, Shriver WG (2008) Population

Editorial responsibility: Michael Reed,

Medford, Massachusetts, USA viability analysis of the Florida grasshopper sparrow (Ammodramus savannarum floridanus): testing recovery goals and management options. Auk 125:167-177

Prakash V (1999) Status of vultures in Keoladeo National Park, Bharatpur, Rajasthan, with special reference to population crash in Gyps species. J Bombay Nat Hist Soc 96:365-378

> Prakash V, Pain DJ, Cunningham AA, Donald PF and others (2003) Catastrophic collapse of Indian white-backed Gyps bengalensis and long-billed Gyps indicus vulture populations. Biol Conserv 109:381-390

Prakash V, Bishwakarma MC, Chaudhary A, Cuthbert R and others (2012) The population decline of Gyps vultures in India and Nepal has slowed since veterinary use of diclofenac was banned. PLoS ONE 7:e49118

Royle JA (2004) N-mixture models for estimating population size from spatially replicated counts. Biometrics 60: 108-115

Royle JA, Dawson DK, Bates S (2004) Modeling abundance effects in distance sampling. Ecology 85:1591-1597

Sandvik H, Erikstad K, Barrett R, Yoccoz N (2005) The effect of climate on adult survival in five species of North Atlantic seabirds. J Anim Ecol 74:817-831

Sarrazin F, Bagnolini C, Pinna J, Danchin E, Clobert J (1994) High survival estimates of griffon vultures (Gyps fulvus fulvus) in a reintroduced population. Auk 111:853-862

Schaub M, Zink R, Beissmann H, Sarrazin F, Arlettaze R (2009) When to end releases in reintroduction programmes: demographic rates and population viability analysis of bearded vultures in the Alps. J Appl Ecol 46: 92-100

Severson K, Plumb G (1998) Comparison of methods to estimate population densities of black-tailed prairie dogs. Wildl Soc Bull 26:859-866

> Shaffer ML (1981) Minimum population sizes for species conservation. Bioscience 31:131-134

> Sharma P (2012) Aceclofenac as a potential threat to critically endangered vultures in India: a review. J Raptor Res 46:314-318

Sibly RM, Hone J (2002) Population growth rate and its determinants: an overview. Philos Trans R Soc Lond B Biol Sci 357:1153-1170

> Snyder N, Derrickson S, Beissinger S, Wiley J, Smith T, Toone W, Miller B (1996) Limitations of captive breeding in endangered species recovery. Conserv Biol 10: 338-348

Thompson WL (2002) Towards reliable bird surveys: accounting for individuals present but not detected. Auk 119:18-25

> Thompson P, Harwood J (1990) Methods for estimating the population size of common seals, Phoca vitulina. J Appl Ecol 27:924-938

Tremblay R (1997) Lepanthes caritensis, an endangered orchid: no sex, no future. Selbyana 18:160-166

White T Jr, Collazo J, Vilella F (2005) Survival of captivereared Puerto Rican parrots released in the Caribbean National Forest. Condor 107:424-432

Zeoli LF, Sayler RD, Wielgus R (2008) Population viability analysis for captive breeding and reintroduction of the endangered Columbian basin pygmy rabbit. Anim Conserv 11:504-512

Submitted: December 3, 2012; Accepted: April 16, 2013

Proofs received from author(s): June 20, 2013 